\title{
Knowledge and Practice of Breast Feeding among Young Adult Women in Rural Tamil Nadu
}

\author{
S. Gayathri Devi ${ }^{1 *}$ and S. Ponne ${ }^{2}$ \\ 'Associate Professor and Head, Department of Home Science, Government Arts and Science College for Women, \\ Bargur-635104, Tamil Nadu, India; sgayathridevi74@gmail.com \\ ${ }^{2}$ Associate Professor, Department of Foods and Nutrition, Vellalar College for Women, \\ Erode - 638012, Tamil Nadu, India
}

\begin{abstract}
The best gift of a mother to her baby is breast milk. The breast feeding practices vary among different regions. Hence the present cross sectional study was conducted among the rural young mothers to evaluate their knowledge about the advantages of breast feeding and to study their breast feeding and sanitary practices. This study was conductedamong 150 women living in 9 villages of Bargur taluk who were selected using convenience sampling method with the inclusion criteria that they were 18 to 25 years old, married and having at least one 1 to 5 years old child. A pretested schedule was used to collect data regarding their general information, knowledge about breast feeding and their breast feeding and sanitary practices. Though all the selected rural mothers were having poor socio economic status, they had a good knowledge about the advantages of breast feeding and correct breast feeding practices. Because of the good sanitary habits of the mothers, their children did not suffer from any infectious diseases for the past fifteen days.
\end{abstract}

Keywords: Breast Feeding, Knowledge, Rural Mothers, Sanitary Practices

\section{Introduction}

Breast feeding is considered beneficial to the mother and the baby. The best source of nutrients to a baby is breast milk. Exclusive breast feeding for six months followed by breast feeding accompanied by complementary feeding up to two years of age is recommended by World Health

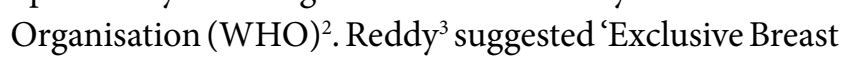
Feeding $(\mathrm{EBF})$ is one where the baby receives only breast milk and no other liquids or solids except drops or syrups of medicines and nutrient supplements'. A crucial role is played by the duration of breast feeding, the time when the baby is weaned and the time of initiation of breast feeding in determining the health of the babyl. Chaudhary et al., [denoted 'WHO had recommended the immediate initiation of breast feeding after birth preferably within half an hour after delivery. This would enable the baby to get colostrum'. The baby should be fed day and night on demand Regional differences in breast feeding practices not only affects the sensory and cognitive development of the children but also protects the children from infectious and chronic diseases. Hence the present cross sectional study was conducted among the rural young mothers to evaluate their knowledge about the advantages of breast feeding and to study the breast feeding and sanitary practices of the selected mothers.

\section{Materials and Methods}

This study was conducted in nine purposively selected villages of Bargur taluk in Krishnagiri district of Tamil Nadu due to easy approachability of the researchers to the people living there. Using convenience sampling method, 150 women who met the following criterion were selected

${ }^{*}$ Author for correspondence 
for the study. Inclusion criterion was married women of 18 to 25 years having at least one child in the age group of 1 to 5 years.

A pretested schedule was used to collect data from the selected women. The schedule contained questions regarding their general information, knowledge about breast feeding, breast feeding practices followed by the mothers and their sanitary practices. Under general information, questions were asked about the name, date of birth, age at marriage, age at first child birth, education completed, monthly income, type of the family, number of family members and details of the spouse. The knowledge of the selected mothers about the advantages of breast feeding was assessed using a set of 10 'Yes/No' type questions. Each correct answer was given a score of ' 1 'and ' 0 ' was given for a wrong answer. A set of multiple choice questions was used to collect data regarding the mother's breast feeding practices. Questions regarding the time of feeding after giving birth, colostrum feeding, type and frequency of feeding, period of exclusive breast feeding, foods included and avoided during breast feeding, inclusion of lacto gauges in the diet and their source of information regarding breast feeding were included to study the breast feeding practices of the selected mothers. The schedule included questions about the sanitary practices followed by the mothers because poor sanitation and unsafe hygiene practices are the main causes of diarrhea which is one of the major reasons of death of $<5$ years old children. The collected data were consolidated, tabulated and analysed.

\section{Results and Discussion}

\subsection{General Information and Socio Economic Status}

Out of the 150 selected mothers (Table 1), 59 percent were 24 to 25 years old and 34 percent were 21 to 23 years old. The age at marriage for 43.3 percent of the women was less than 18 years and for 56.7 percent of the mothers, it was more than 18 years. Among these women, 12 percent had their first baby before they were 18 years old. Majority of the mothers (48.66\%) had their first baby between 19 and 21 years of age. Nearly 39 percent of the women had completed only primary level of education and all of them belonged to the economically weaker section with less than Rs. 8000 as monthly income. Almost half of them (51.3\%) were living in nuclear family and 40.7 percent had seven to nine members in the family. Nearly 30 percent of them were having four to six members in the family. More than half of the women's spouses were 21 to 25 years old (55.6\%), had completed secondary education (56\%) and farmers (53.3\%).

Table 1. General information and socio economic status of the women

\begin{tabular}{|c|c|c|c|c|}
\hline S.No. & Criteria & Classification & Number $(\mathrm{N}=150)$ & Percentage \\
\hline \multirow[t]{3}{*}{1} & \multirow[t]{3}{*}{ Age at present (Years) } & $18-20$ & 11 & 7 \\
\hline & & $21-23$ & 51 & 34 \\
\hline & & $24-25$ & 88 & 59 \\
\hline \multirow[t]{2}{*}{2.} & \multirow[t]{2}{*}{ Age at marriage (Years) } & $16-18$ & 65 & 43.3 \\
\hline & & $19-25$ & 85 & 56.7 \\
\hline \multirow[t]{4}{*}{3.} & \multirow[t]{4}{*}{ Age at first child birth (Years) } & $\leq 18$ & 18 & 12 \\
\hline & & $19-21$ & 73 & 48.66 \\
\hline & & $22-24$ & 48 & 32 \\
\hline & & $\geq 25$ & 8 & 5.33 \\
\hline \multirow[t]{5}{*}{4.} & \multirow[t]{5}{*}{ Education completed } & Illiterate & 17 & 11.3 \\
\hline & & Primary & 59 & 39.3 \\
\hline & & Secondary & 27 & 18 \\
\hline & & Higher secondary & 19 & 12.7 \\
\hline & & Higher education & 28 & 18.7 \\
\hline \multirow[t]{4}{*}{5.} & \multirow[t]{4}{*}{ Number of family members } & $\leq 3$ & 33 & 22 \\
\hline & & $4-6$ & 46 & 30.3 \\
\hline & & $7-9$ & 60 & 40.3 \\
\hline & & $\geq 10$ & 11 & 7.4 \\
\hline
\end{tabular}




\subsection{Mother's Knowledge about Breast Feeding}

All the selected mothers had a good knowledge about the advantages of breast feeding to the mothers and the children. The minimum score 8 was obtained by $3 \%$ of mothers and 90 percent of the mothers had obtained the maximum score of 10 (Figure 1). Mekuria and Edris] stated About 61 percent of the mothers did not have adequate knowledge about breast feeding and exclusive breast feeding was practiced by 2.57 times more by the mothers who had adequate knowledge about the same.

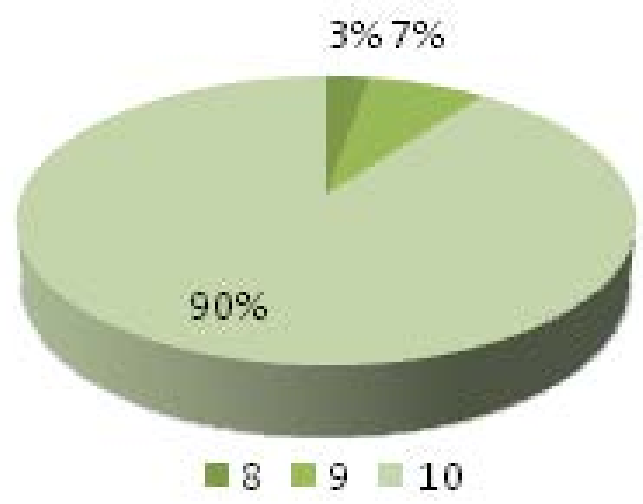

Figure 1. Score obtained by the mothers.

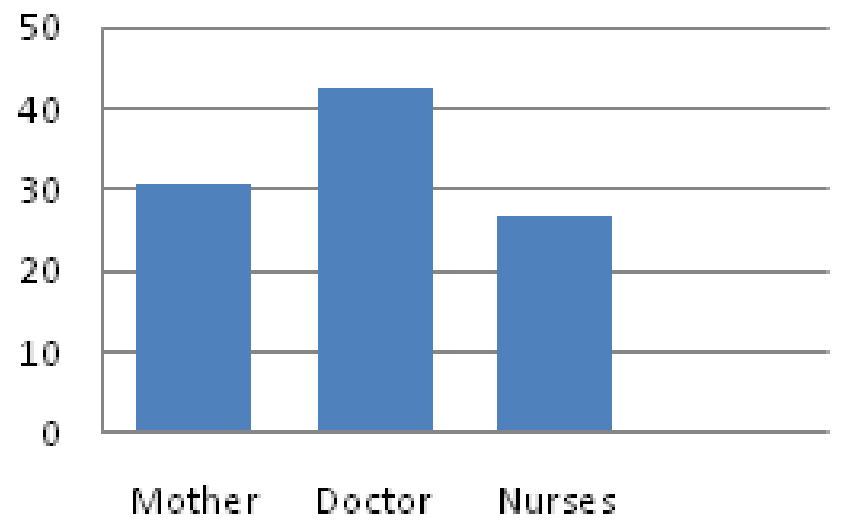

Figure 2. Source of information.

\subsection{Breast Feeding Practices of the Mothers}

It can be noted from Table 2 that 64.66 percent of the mothers had breast fed their babies within half an hour after birth and 21.33 percent of the mothers started breast feeding between one and two hours after birth. Feeding of colostrum was reported by 98 percent of the mothers. According to Dandekar et al., 9 'Colostrum was fed by 77.6 percent of the mothers'. His study also showed 'Breast feeding was initiated within one hour after delivery by 41.6 percent of the mothers and exclusive breast feeding was seen in 79.2 percent of the mothers but this rate reduced with an increase in the level of education'. In this study, exclusive breast feeding was done by all the mothers even though 69 percent of them had completed only secondary level of education and their knowledge about the advantages of breast feeding was also more.

Table 2. Time of initiation of breast feeding by the mothers

\begin{tabular}{|l|c|c|}
\hline $\begin{array}{l}\text { Initiation of breast } \\
\text { feeding }\end{array}$ & Number $(\mathrm{N}=150)$ & Percentage \\
\hline$\leq 30$ minutes & 97 & 64.66 \\
\hline 1-2hours & 32 & 21.33 \\
\hline 2-6hours & 14 & 9.33 \\
\hline After a day & 7 & 4.66 \\
\hline
\end{tabular}

It was also seen that all of them (100\%) followed interval feeding and 74.66 percent of them fed the babies 6 times per day. Demand feeding was practiced by only17.5 percent of the mothers in the study done by Chinnasam et al . Comparatively better breast feeding practices than the previous studies were observed by Mohan et al., 1 in a semi urban location of Tamil Nadu. Majority of the mothers (96.66\%) told that they did not include or avoid any food during lactation and did not use any lacto gauges.

Information about breast feeding was given to the selected women by doctors (42.66\%), mothers (30.66\%) and nurses $(26.66 \%)$ as depicted in Figure 2. Bhattathiry and Ethirajan also noticed that the information about health care was obtained from health care workers by 69 percent of the women. According to Chinnasam et al., 'When doctors were preferred as counselors there was a positive impact on breast feeding' .

\subsection{Sanitary Practices of the Mothers}

In general it was observed that the mothers were having good sanitary practices. All the women informed that they had the habit of washing hands before cooking, after using toilet and before eating. But 12.66 percent of them washed with water and 87.33 percent used soap. All of them used to wash food stuffs before 
cooking. All the mothers reported to wash the breasts before feeding the baby and maintained their hair and nails properly. Presence of infections such as diarrhea, respiratory infections, vomiting and fever were noted in the children of very few mothers $(1.33 \%, 6 \%, 3.33 \%$ and $4 \%$ respectively) during the past fifteen days. Duncan 12 reported 'Decrease in unsafe water, unsafe sanitation and unsafe hand hygiene paralleled a decrease in deaths due to diarrheal diseases'.

\section{Conclusion}

Although the selected rural mothers belonged to poor socio economic status their knowledge about the advantages of breast feeding was good and they had correct breast feeding practices also. As the selected mothers had good sanitary habits their children did not suffer from any infectious diseases for the past fifteen days.

\section{References}

1. Motee A, Deerajen R, Prity P, Rajesh J. An assessment of the breast feeding practices and infant feeding pattern among young mothers in Mauritius. Journal of Nutrition and Metabolism. 2013:16-3.

2. Ku C, Chow SKY. Factors influencing the practice of exclusive breast feeding among Hong Kong Chinese women: A questionnaire survey. Journal of Clinical Nursing. 2010; 19(17-18):2432-45. https://doi.org/10.1111/j.13652702.2010.03302.x PMid:20920071.

3. Reddy S. Determinants of exclusive breast feeding practice among mothers of children under two years old in Dillza Zuria district Gedeo zone, Ethiopia. Journal of Pregnancy and Child Health. 2014; 5(3):2-6.
4. Sadasivam M. Prelacteal feeding practice among rural mothers in Tamil Nadu- A questionnaire based study. International Journal of Biomedical and Advanced Research. 2015; 6(06):484-7.

5. Chaudhary RN, Shah T, Raja S. Knowledge and practice of mothers regarding breast feeding: A hospital based study. Health Renaissance. 2011; 9(3):194-200. https://doi. org/10.3126/hren.v9i3.5590.

6. Stuart C, Christoph L. Obstetrics by ten teachers. 17th ed. United Kingdom: Taylor and Francis; 2000.

7. Mekuria G, Edris M. Exclusive breast feeding and associated factors among mothers in Debre Marcos, Northwest Ethiopia: A cross sectional study. International Breast Feeding Journal. 2015; 10:1. https://doi.org/10.1186/ s13006-014-0027-0 PMid:25635183 PMCid:PMC4310186.

8. Dandekar RH, Mohd Shafee, Kumar R. Breast feeding and weaning practices among literate mothers: A community based study in rural area of Perumbakkam Taluk, Tamil Nadu. The Health Agenda. 2014; 2(1).

9. Chinnasam B, Sundaramoorthy S, Sadasivam K, Pasupathy $\mathrm{S}$. Knowledge, attitude and practices of mothers regarding breastfeeding in a South Indian hospital. Biomed Pharmacol J. 2016; 9(1).

10. Mohan Y, Jain T, Dutta R, Parasuraman G. Does literary status of mother influence breast feeding practices: Experience from a semi urban location in Tamil Nadu. International Journal of Community Medicine and Public Health. 2017; 4(8). https://doi.org/10.18203/2394-6040. ijcmph20173115.

11. Bhattathiry MM, Ethirajan N. Unmet need for family planning among married women of reproductive age group in urban Tamil Nadu. J Family Community Med. 2014; 21(1):53-7. https://doi.org/10.4103/2230-8229.128786 PMid:24696634 PMCid:PMC3966097.

12. Duncan M. Disease priorities in Zimbabwe. Am J Trop Med Hyg. 2016; 95(1):248-9. https://doi.org/10.4269/ajtmh.16-0130a PMid:27385667 PMCid:PMC4944698 